\title{
Extreme lipomatous hypertrophy of the interatrial septum presenting as cardiac mass extending into the pericardium, confirmed by cardiac magnetic resonance
}

\author{
Maciej Pruski ${ }^{1}$, Wojciech Wróbel ${ }^{1}$, Karolina Wrona $^{1}$, Dominika Spyra-Skrabaczewska ${ }^{1}$, \\ Klaudia Męcka ${ }^{1}$, and Katarzyna Mizia-Stec ${ }^{1}$ \\ ${ }^{1}$ Medical University of Silesia School of Medicine in Katowice
}

August 16, 2021

\begin{abstract}
Lipomatous hypertrophy of the interatrial septum is a relatively common disorder that occasionally presents as cardiac mass. Here, we present a case of extreme lipomatous hypertrophy up to $4 \mathrm{~cm}$ in diameter and extending into the epicardium, posterior wall of the right atrium and the atrioventricular sulcus. Diagnosis was confirmed by transesophageal echocardiography and cardiac magnetic resonance imaging.
\end{abstract}

Title: Extreme lipomatous hypertrophy of the interatrial septum presenting as cardiac mass extending into the pericardium, confirmed by cardiac magnetic resonance

Running title: Extreme Lipomatous hypertrophy

Authors: Maciej Pruski, MD; Wróbel Wojciech, MD; Wrona Karolina, MD; Sypra-Skrabaczewska Dominika, MD; Męcka Klaudia, MD; Mizia-Stec Katarzyna, Md, PhD

All authors affiliated with:

First Department of Cardiology

School of Medicine in Katowice

Medical University of Silesia, Katowice, Poland

Head of Department: Prof. Katarzyna Mizia-Stec, MD, PhD

PL-40-635 Katowice, Ziolowa 47, Poland

tel. $+4832-3598890$

fax $+4832-2523658$

Corresponding Author: Maciej Pruski, MD maciejpruski87@gmail.com phone: +48603801216

Sources of funding: none

Abstract:

Lipomatous hypertrophy of the interatrial septum is a relatively common disorder that occasionally presents as cardiac mass. Here, we present a case of extreme lipomatous hypertrophy up to $4 \mathrm{~cm}$ in diameter and extending into the epicardium, posterior wall of the right atrium and the atrioventricular sulcus. Diagnosis was confirmed by transesophageal echocardiography and cardiac magnetic resonance imaging. 
Lipomatous hypertrophy of the interatrial septum (IAS) is a common and usually benign lesion that occasionally presents as intracardiac mass and necessitates diagnostic workup [1-4]. The differential diagnosis includes cardiac tumors such as cardiac lipoma, myxoma, cardiac liposarcoma, metastases and others. The typical features are sparing of the fossa ovalis and lack of a capsule. Cardiac magnetic resonance (CMR) is frequently helpful in confirming the diagnosis [5]. The lesion exhibits characteristics typical of fat tissue on CMR (high signal in T1-weighted images and T2 nonfat-suppressed images, and low signal in fat suppressed imaging). It has been associated with atrial arrythmias that are occasionally resistant to pharmacotherapy [6] and can also cause superior vena cava (SVC) syndrome when there is compression of the SVC. Rarely, it can be associated with sudden cardiac death or intractable symptoms that require surgical treatment $[7,8]$. Here, we present an unusual case of extreme lipomatous hypertrophy presenting as cardiac mass that extended into the epicardium, posterior wall of the right atrium and the atrioventricular sulcus.

The patient is a 67-year-old female with history of chronic cigarette smoking, obesity (BMI 31.2) and hypertension. She complained of shortness of breath on exertion in NYHA II functional class and infrequent palpitations. There was no history of syncope. Blood teste were normal. An echocardiogram was performed upon admission, that revealed an oval mass originating in the IAS with up to $4 \mathrm{~cm}$ in diameter (Figure 1). The echogenicity of the mass was similar to that of other parts of the IAS and the fossa ovalis was spared suggesting the diagnosis of extreme lipomatous hypertrophy. A transesophageal echocardiogram was also performed, which showed a mass with dimensions $38 \times 41 \mathrm{~mm}$ in the IAS, sparing of the fossa ovalis and a reduction of SVC diameter without flow acceleration in color doppler (Figure 2). On CMR examination lipomatous hypertrophy of the anterior part of the IAS was noted as well as a large unencapsulated mass in the posterior part of the IAS with tissue characteristics of fatty tissue, that encompassed the posterior part of the IAS and extended into the epicardium, posterior wall of the right atrium and the atrioventricular sulcus. Fossa ovalis was preserved. There were no signs of perfusion or enhancement of the mass on contrast examination (Figure 3). SVC was mildly compressed by the mass, with no signs of compression of the inferior vena cava or right ventricle inflow tract. LGE imaging showed intramural and subepicardial enhancement in inferior and middle segments of the interventricular septum, without typical ischemic scars. A 24-hour Holter ECG examination revealed a single episode of atrial tachycardia with atrial rate of 130 BPM and ventricular rate of $110 \mathrm{BPM}$ consisting of 6 QRS complexes as well as 5419 supraventricular premature beats. No ventricular arrhythmia or conduction abnormalities were noted. Finally, the patient was reassured of the benign nature of the lesion, however, because of extremely disseminated heart involvement an ambulatory CMR was scheduled to check for progression of the disease in the SVC area.

Author contributions: All authors contributed in obtaining patient and imaging data as well as in drafting and critical revision of the manuscript.

References:

1. O'Connor S, Recavarren R, Nichols LC, et al: Lipomatous hypertrophy of the interatrial septum: an overview. Arch Pathol Lab Med 2006;130:397-9

2. Heyer CM, Kagel T, Lemburg SP, et al: Lipomatous hypertrophy of the interatrial septum: a prospective study of incidence, imaging findings, and clinical symptoms. Chest 2003;124:2068-73.

3. Burke AP, Litovsky S, Virmani R: Lipomatous hypertrophy of the atrial septum presenting as a right atrial mass. Am J Surg Pathol 1996;20:678-85.

4. Lampropoulos KM, Kotsas D, Iliopoulos T: Lipomatous hypertrophy of interatrial septum. BMJ Case Rep. 2012;2012:bcr2012006611. Published 2012 Sep 21. doi:10.1136/bcr-2012-006611

5. Bussani R, Castrichini M, Restivo L, et al: Cardiac Tumors: Diagnosis, Prognosis, and Treatment. Current cardiology reports, 22(12), 169. https://doi.org/10.1007/s11886-020-01420-z

6. Hutter AM, Page DL: Atrial arrhythmias and lipomatous hypertrophy of the cardiac interatrial septum. Am Heart J 1971;82:16-21. 
7. Verberkmoes NJ, Kats S, Tan-Go I, et al: Resection of a lipomatous hypertrophic interatrial septum involving the right ventricle. Interact Cardiovasc Thorac Surg. 2007 Oct;6(5):654-7. doi: 10.1510/icvts.2007.157776. Epub 2007 Jul 11. PMID: 17670727.

8. Nadra I, Dawson D, Schmitz SA, et al.: Lipomatous hypertrophy of the interatrial septum: a commonly misdiagnosed mass often leading to unnecessary cardiac surgery. Heart 2004;90:e66.
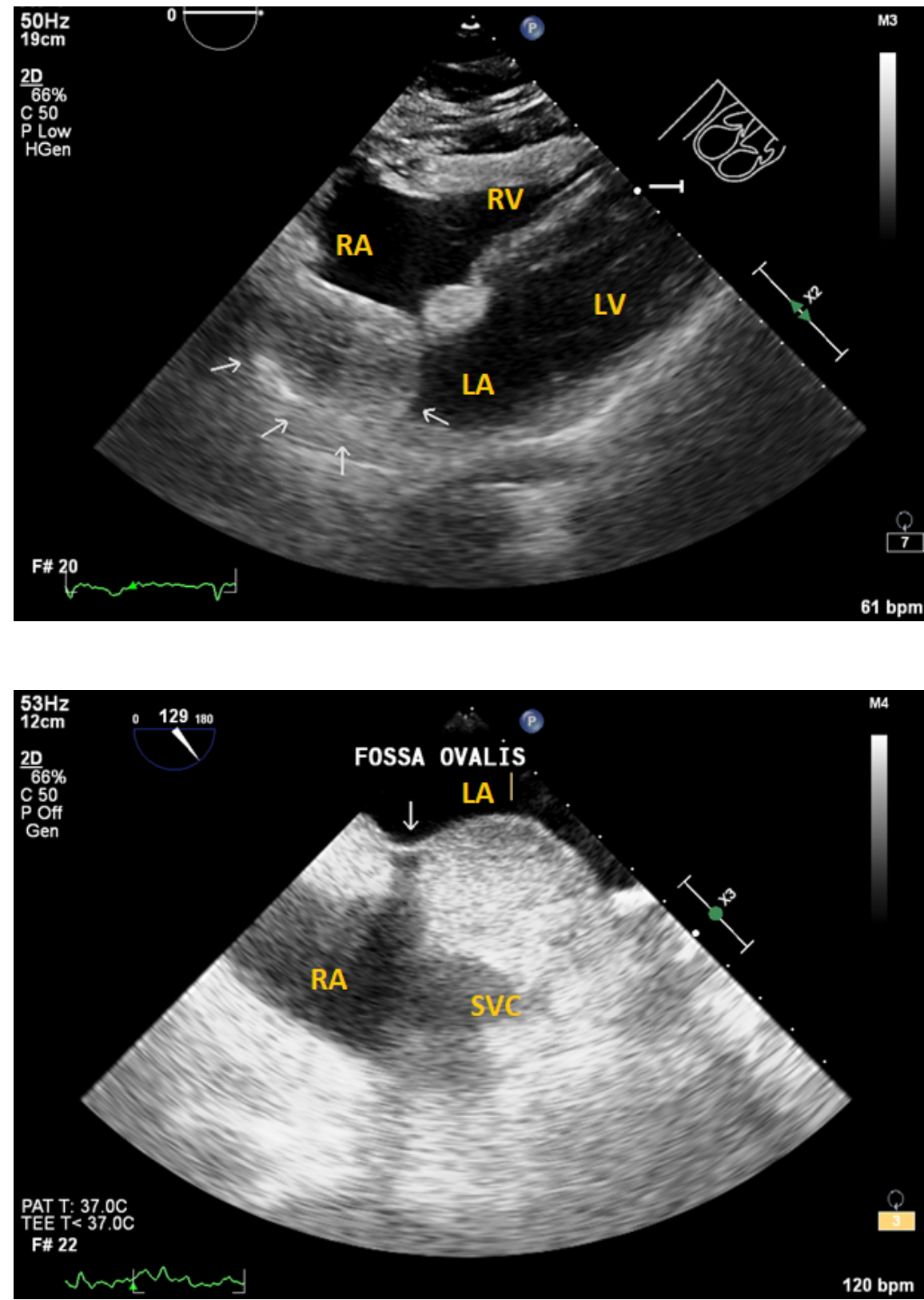


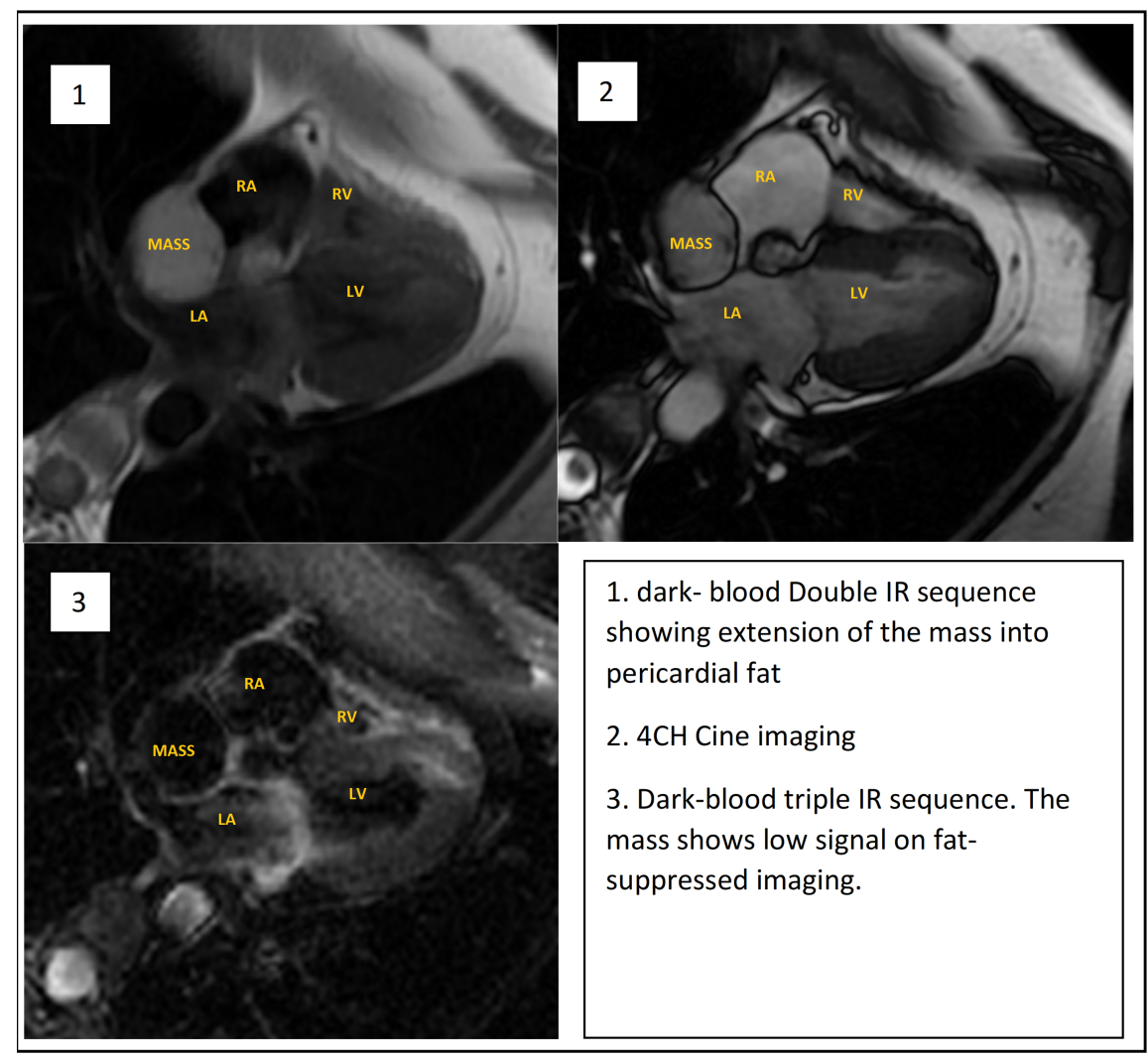

